\title{
Development of a Rapid Diagnostic Test Kit to Detect IgG/ IgM Antibody against Zika Virus Using Monoclonal Antibodies to the Envelope and Non-structural Protein 1 of the Virus
}

\author{
Yeong Hoon Kim ${ }^{1, \dagger}$, Jihoo Lee ${ }^{2, \dagger}$, Young-Eun Kim², Chom-Kyu Chong², Yanaihara Pinchemel ${ }^{3}$, Francis Reisdörfer', \\ Joyce Brito Coelho ${ }^{3}$, Ronaldo Ferreira Dias ${ }^{3}$, Pan Kee Bae ${ }^{4}$, Zuinara Pereira Maia Gusmão ${ }^{5}$, Hye-Jin Ahn ${ }^{6}$, Ho-Woo Nam,** \\ ${ }^{1}$ Department of Ophthalmology, College of Medicine, Catholic University of Korea, Seoul 06591, Korea; 'enBody Inc., Cheonan 31116, Korea; \\ ${ }^{3}$ Bahiafarma, Simoes Filho, Bahia, Brazil; ${ }^{3}$ BioNano Health Guard Research Center, Daejeon 34141, Korea; ${ }^{5}$ Lacen-ba, Laboratorio Central, Bahia, \\ Brazil; ${ }^{6}$ Department of Parasitology, College of Medicine, Catholic University of Korea, Seoul 06591, Korea
}

\begin{abstract}
We developed a Rapid Diagnostic Test (RDT) kit for detecting lgG/lgM antibodies against Zika virus (ZIKV) using monoclonal antibodies to the envelope (E) and non-structural protein 1 (NS1) of ZIKV. These proteins were produced using baculovirus expression vector with Sf9 cells. Monoclonal antibodies J2G7 to NS1 and J5E1 to E protein were selected and conjugated with colloidal gold to produce the Zika lgG/lgM RDT kit (Zika RDT). Comparisons with ELISA, plaque reduction neutralization test (PRNT), and PCR were done to investigate the analytical sensitivity of Zika RDT, which resulted in $100 \%$ identical results. Sensitivity and specificity of Zika RDT in a field test was determined using positive and negative samples from Brazil and Korea. The diagnostic accuracy of Zika RDT was fairly high; sensitivity and specificity for lgG was 99.0 and $99.3 \%$, respectively, while for lgM it was 96.7 and $98.7 \%$, respectively. Cross reaction with dengue virus was evaluated using anti-Dengue Mixed Titer Performance Panel (PVD201), in which the Zika RDT showed crossreactions with DENV in $16.7 \%$ and $5.6 \%$ in $\operatorname{lgG}$ and IgM, respectively. Cross reactions were not observed with West Nile, yellow fever, and hepatitis C virus infected sera. Zika RDT kit is very simple to use, rapid to assay, and very sensitive, and highly specific. Therefore, it would serve as a choice of method for point-of-care diagnosis and large scale surveys of ZIKV infection under clinical or field conditions worldwide in endemic areas.
\end{abstract}

Key words: Zika, flavivirus, diagnostics, RDT, monoclonal antibody, envelope, NS1, cross reaction

\section{INTRODUCTION}

Zika virus (ZIKV) is a mosquito-borne, single stranded RNA flavivirus that was first identified in the Zika forest of Uganda in 1947 from Rhesus monkeys [1]. Some cases of human infection were reported in Africa and Asia [2,3] before the first major outbreak on the island of Yap in the Federated States of Micronesia in 2007 [4]. ZIKV spread to the American continent [5], and its emergence was associated with the description of severe neurological complications; Guillain-Barré syndrome (GBS) in adults in French Polynesia and microcephaly in neonates in Brazil $[6,7]$.

Most ZIKV-infected patients are asymptomatic [4]. On the

- Received 16 October 2017, revised 15 January 2018, accepted 20 January 2018. *Corresponding author (howoo@catholic.ac.kr)

'Both authors contributed equally to this work.

(c) 2018, Korean Society for Parasitology and Tropical Medicine

This is an Open Access article distributed under the terms of the Creative Commons Attribution Non-Commercial License (http://creativecommons.org/licenses/by-nc/4.0) which permits unrestricted non-commercial use, distribution, and reproduction in any medium, provided the original work is properly cited. other hand, most of those who do have them have symptoms that are almost indistinguishable from those of other causes of undifferentiated systemic febrile illness, especially dengue (DENV) and chikungunya virus infections. To further confuse the issue, these infections are also transmitted by the Aedes mosquito and are found in the same regions as ZIKV infections [8]. Furthermore, co-infections with these viruses have also been reported $[9,10]$. Additionally, these viral infections could share the transmission routes.

ZIKV is primarily transmitted to people through the bite of an infected Aedes mosquito, mainly Aedes aegypti and Aedes albopictus, which are the same mosquitoes that transmit dengue, chikungunya, and yellow fever viruses. Sexual transmission and transmission through laboratory exposure are possible, and it is also theoretically possible through blood transfusion, organ and tissue transplant, fertility treatment, and breast feeding. Interestingly, ZIKV can also be transmitted through other non-vector-borne routes, including sexual intercourse, transplacental transmission, blood product transfusion, and possi- 
bly exposure to other bodily fluids with high viral loads $[8,11$ 14]. Thus, the diagnosis of ZIKV infection cannot be reliably established by clinical features alone.

As evidenced by a number of recently emerging viral epidemics, highly sensitive and specific laboratory diagnostics for these infections are essential for infection control measures [15-17]. Reverse transcriptase-PCR (RT-PCR) has been the most commonly used laboratory diagnostic assay for ZIKV infection worldwide. A number of specific real-time and conventional RT-PCR assays targeting the envelope (E), premembrane (prM), nonstructural proteins 1 (NS1), NS2B, NS3, and NS5 gene coding regions of the ZIKV genome have been described [18-24]. However, most of these assays were developed before the ZIKV epidemic occurred in the Americas, and there are up to 10 potential nucleotide mismatches between the sequences of the individual assays' primers and current epidemic virus strains [25]. The low sensitivity in these assays may also lead to false-negative results in up to $20-80 \%$ of patients, especially those with low viral loads in their blood or urine [25].

Thus, laboratory diagnosis of ZIKV infection is very important, but remains challenging, due to a limited time window of possible virus detection, whereby patients tested more than 1 to 2 weeks post-symptom onset are difficult to diagnose [2628]. There is therefore a need for an accurate diagnostic approach that will prolong the diagnostic period [29]. In this study, we developed an RDT kit (Zika RDT) for detecting IgG/ IgM antibody against ZIKV using monoclonal antibodies to the E and NS1 proteins of ZIKV.

\section{MATERIALS AND METHODS}

\section{Ethics statement}

This study was performed under the regulation of the IRB Committee of FEMPTEC (2016-06-01) and the IRB Committee of BahiaFarma (2016-01-02). This research adhered to the tenets of the Declaration of Helsinki. All participants provided written informed consent, and no minors were involved in the study. All procedures and handling of mice were conducted under an approved protocol by the Institutional Animal Care and Use Committee (IACUC) at the School of Medicine, Catholic University of Korea (CUMC-2015-0042-02, 20152017), which adhered to the regulations set under the Korean National Animal Protection Act.

\section{Expression of fusion protein}

Nonstructural 1 (NS1) and Envelope (E) proteins were used as diagnostic target of anti-ZIKV. The particular NS1 sequence (354 aa) and E sequence (261 aa) were obtained from the Swiss Institute of Bioinformatics (http://viralzone.expasy.org).

We produced recombinant NS1 and E proteins of ZIKV through recombinant baculovirus expression vector technology with Sf9 cells. The pAcGP67a-NS1-his and pAcGP67a-Envhis vectors were cloned. Briefly, Spodoptera frugiperda Sf9 cells (ATCC \#CRL-1711) were grown at $27^{\circ} \mathrm{C}$ in Sf-900II serum-free medium (Gibco/BRL, Gaithersburg, Maryland, USA) with $10 \%$ fetal bovine serum (FBS). The Sf9 cells were transfected with pAcGP67a-NS1-his and PAcGP67a-Env-his vector by polyfect-mediated method (Hilden, Qiagen, Germany). The cells were incubated at $27^{\circ} \mathrm{C}$ for $72 \mathrm{hr}$, and then infected with recombinant baculoviruses at a multiplicity of infection (MOI) $0.01-10$. Following 7 days of incubation at $27^{\circ} \mathrm{C}$ the cells were removed from culture medium. The supernatant was collected and analyzed on SDS-PAGE and western blot. With the cold centrifugation at 3,000 $\mathrm{g}$ for $10 \mathrm{~min}$, the collected supernatant was introduced to pre-equilibrated $\mathrm{Ni}^{2+}$-nitrilotriacetic acid (Ni-NTA) resin (Qiagen). Elution was performed using 5 and $500 \mathrm{mmol} / \mathrm{L}$ imidazole in $20 \mathrm{mmol} / \mathrm{L}$ Tris-Cl (pH 8.0). The eluate was dialyzed using Tris-Cl (pH 8.0) for $24 \mathrm{hr}$ by changing the buffer thrice. Western blot against Zika positive and antihIgG-HRP, and SDS-PAGE were performed after purification.

\section{Immunization of mice with the recombinant ZIKV NS1 and $\mathrm{E}$}

The recombinant proteins $(100 \mu \mathrm{g} / 250 \mu \mathrm{l})$ were mixed with equal volumes of Freund's complete adjuvants (Sigma Chemical Co., St. Louis, Missouri, USA), and the mixture was injected intraperitoneally into 6-weeks-old female BALB/c mice (Samtaco, Suwon, Korea). The second and third injections were followed with the same amount of protein mixed with incomplete Freund's adjuvant (Sigma-Aldrich, St. Louis, Missouri, USA) in the same way at 2-week intervals. After the third immunization, the recombinant proteins $(100 \mu \mathrm{g} / 250 \mu \mathrm{l})$ were injected intravenously without adjuvant.

\section{Hybridoma cell cloning}

To produce hybridoma cell-secreted monoclonal antibodies (mAbs), we used a cell fusion technique according to an established protocol [30,31]. Mouse myeloma cells (SP2/0 cell; ATCC \#CRL 1581) were fused with spleen cells from the donor 
mice using 50\% polyethylene glycol (Sigma Chemical Co.). After incubation with hypoxanthine, aminopterin, and thymidine media (Sigma Chemical Co.), supernatants of hybridoma cell culture were screened by ELISA using the recombinant ZIKV NS1 or E proteins $(1 \mu \mathrm{g} / \mathrm{ml})$ as an antigen. After subcloning with limiting dilutions, selected hybridoma colonies were transferred into $25 \mathrm{~cm}^{2}$ tissue culture flasks (Nunc, Roskilde, Denmark) with RPMI-1640 medium (Gibco/BRL) containing 10\% FBS (Gibco/BRL).

\section{Characterization of mAbs}

The mAb-containing supernatant and ascitic fluid of BALB/C mice were collected and screened using ELISA to determine the antibody properties. The mAbs were purified on a protein $\mathrm{G}$ agarose resin (Amicogen, Inc, Jinju, Korea) and identified using SDS-polyacrylamide gel electrophoresis and western blotting. The mAb isotypes were determined using goat anti-mouse immunoglobulins (Sigma-Aldrich), according to the manufacturer's instructions. An indirect competitive ELISA was conducted to measure the affinity of mAbs, as previously described [32]. Various concentrations of the recombinant NS1 or E antigen were incubated with mAbs for $1 \mathrm{hr}$ at room temperature (RT). This antigen-antibody mixture was then transferred to wells where recombinant antigens are coated. After 1-hr incubation at RT, wells were rinsed with PBS containing 0.1\% Tween-20. A 1-hr incubation was followed with anti-mouse IgG-horseradish peroxidase (HRP) conjugate at RT and 3,3'5,5'-tetramethylbenzidine solution was added after final washing. Finally, the absorbance was measured by a microplate reader (Benchmark Plus; Bio-Rad, Hercules, California, USA) at $450 \mathrm{~nm}$ after the termination of coloring reaction by $\mathrm{H}_{2} \mathrm{SO}_{4}$. Dissociation constant (Kd) was calculated by generating Klotz plot.

\section{Preparation and interpretation of the Zika lgG/lgM RDT kit} Monoclonal antibodies J2G7 to NS1 and J5E1 to E proteins were selected from these hybridomas and then conjugated with colloidal gold particles (40 nm in mean diameter) according to a previously described procedure [33] to produce the Zika IgG/IgM RDT kit (Zika RDT; Fig. 1).

Briefly, the assay is performed by adding $5 \mu \mathrm{l}$ of serum/plasma or $10 \mu \mathrm{l}$ of whole blood, and 3-4 drops of the assay buffer. Reacting bands were read after 15-20 min and its density was determined arbitrarily as $0,+,++$, and +++ . Definite reactivity was determined as ++ (mid), while weaker and stronger reactivity compared to it was determined as + (weak) and +++ (strong). The final results were agreed upon by 3 investigators (Fig. 2).

\section{Evaluation of sensitivity and specificity of Zika RDT}

To investigate the analytical sensitivity of RDT, comparison with ELISA, plaque reduction neutralization test (PRNT) and PCR was performed on 30 Zika Positive Specimens provided by the Hospital Gaffree e Guinle (Rio de Janeiro, Brazil). Real-Time RT-PCR (RealStar Zika RT-PCR Kit and AccuPower ZIKA RealTime RT-PCR Kit) is the only method officially approved and used as the gold standard diagnostic method. Supernatant samples $(100 \mu \mathrm{l})$ or serum samples $(1 \mu \mathrm{l}$ and sample diluent $99 \mu \mathrm{l})$ were applied to wells of the ELISA. A sample was considered positive if the optical density (OD) at $490 \mathrm{~nm}$ with a spectrophotometer (Perkin Elmer Victor3, Turku, Finland) was 2-fold

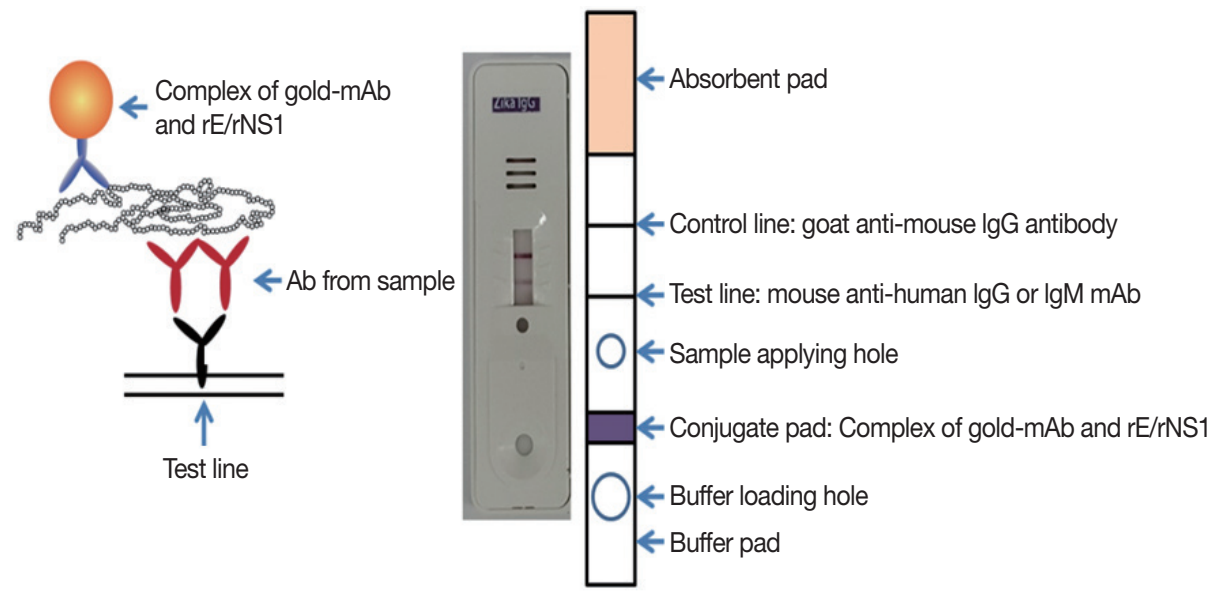

Fig. 1. Schematic working principle and the component of ZIKV IgG/lgM RDT kit. Antibody capturing method was applied and 1 more hole for smaller sample application. 


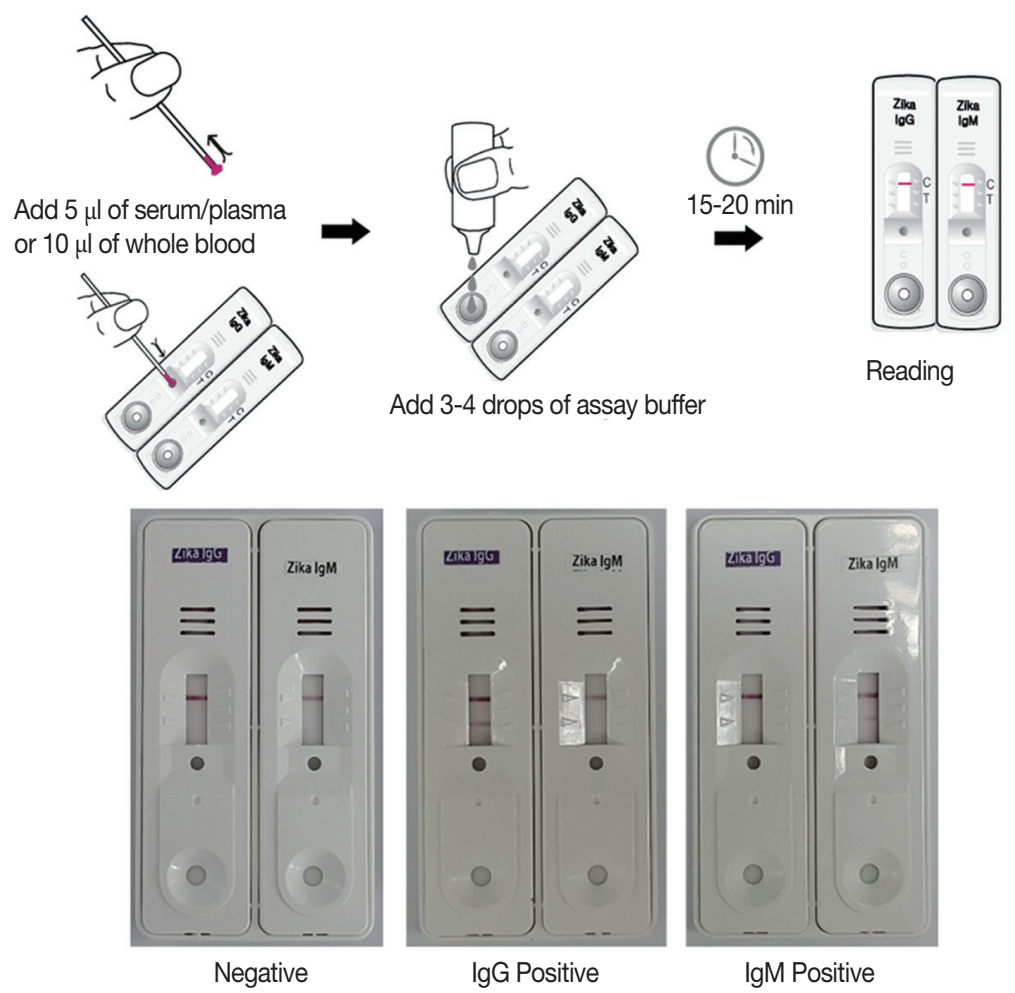

Fig. 2. Working procedure of the Zika lgG/lgM RDT kit and the results of the assay. The procedure does not require any specific technic, can be tested easily and rapidly, and showed clear results.

greater than that of a blank (PBS) sample. The cut-off value was set at twice the average value of the blank sample in 3 replicates.

PRNT was performed to determine the presence of virusspecific neutralizing antibodies in paired serum samples. Briefly, Vero cells were seeded at a density of 160,000 cells/well $24 \mathrm{hr}$ before infection in 6-well plates. De-complemented sera samples $\left(30 \mathrm{~min}\right.$ at $56^{\circ} \mathrm{C}$ ) were 2 fold serially diluted from 1 : 10 to 1:400 in DMEM serum-free medium. Then an equal volume of DMEM-diluted ZIKA virus containing 200 PFU was added and incubated for $1 \mathrm{hr}$ at $36^{\circ} \mathrm{C}$ in a final volume of 200 $\mu \mathrm{l}$. Vero cells were infected in duplicate with $100 \mu \mathrm{l}$ of the neutralization mixture and incubated for $1 \mathrm{hr}$ at $37^{\circ} \mathrm{C}$. Afterwards, the viral inoculum was removed and cells were overlaid with 2 $\mathrm{ml}$ of DMEM with 2\% FBS and 1.5\% SeaPlaque agarose (Lonza). Plates were incubated at $37^{\circ} \mathrm{C}$ for 3-5 days. After this period, cells were washed twice with PBS, stained with $1 \%$ crystal violet for $30 \mathrm{~min}$. Plaques were counted and percentage of plaque reduction against control serum was calculated.

RNA extracts from serum samples were prepared for PCR using an ExiPrep Viral RNA Kit (Bioneer Co., Daejeon, Korea). Viral RNA was extracted from $20 \mu \mathrm{l}$ of serum and eluted in 50 $\mu \mathrm{l}$ of elution buffer. For the AccuPower ZIKV Multiplex Real- time RT-PCR assay, $5 \mu$ of RNA extract was mixed with $45 \mu \mathrm{l}$ of master mix, and real-time RT-PCR was performed using a PCR thermocycler (Exicycler 96 Real-Time Quantitative Thermal Block; Bioneer Co., Korea). All of the procedures were performed according to the manufacturer's instructions.

\section{Sensitivity and specificity of Zika RDT in field test}

Positive samples were kindly provided from the Hospital Gaffree e Guinle (Rio de Janeiro, Brazil) under the FEMPTEC foundation and Ministry of Bahia (Brazil), which had been collected from screening procedures in an endemic area. Negative samples were kindly provided from the Dankook University Hospital (Cheonan, Korea) for a field test using ELISA as control.

The sera of 300 positive and 300 negative samples were checked for the $\operatorname{IgG}$, and 150 positive and 300 negative samples were checked for the IgM antibody titers by ELISA. The optical density (OD) of duplicated samples were measured at $490 \mathrm{~nm}$ with a spectrophotometer (Perkin Elmer Victor3) and compensated by comparing the OD of a standard positive serum in each plate.

Cross reactions with DENV were evaluated using anti-Den- 
gue Mixed Titer Performance Panel (PVD201). Cross reactions with West Nile, yellow fever, and hepatitis C virus (HCV) were also determined.

\section{RESULTS}

\section{Construction of a highly specific RDT kit}

ZIKV E and NS1 proteins were exposed to the surface of the virus to be candidate targets as antigens. DNA sequences for the E and NS1 each were obtained from the Swiss Institute of Bioinformatics (http://viralzone.expasy.org) and cloned for the 261 amino acids of $\mathrm{E}$ and 354 amino acids of NS1 proteins.
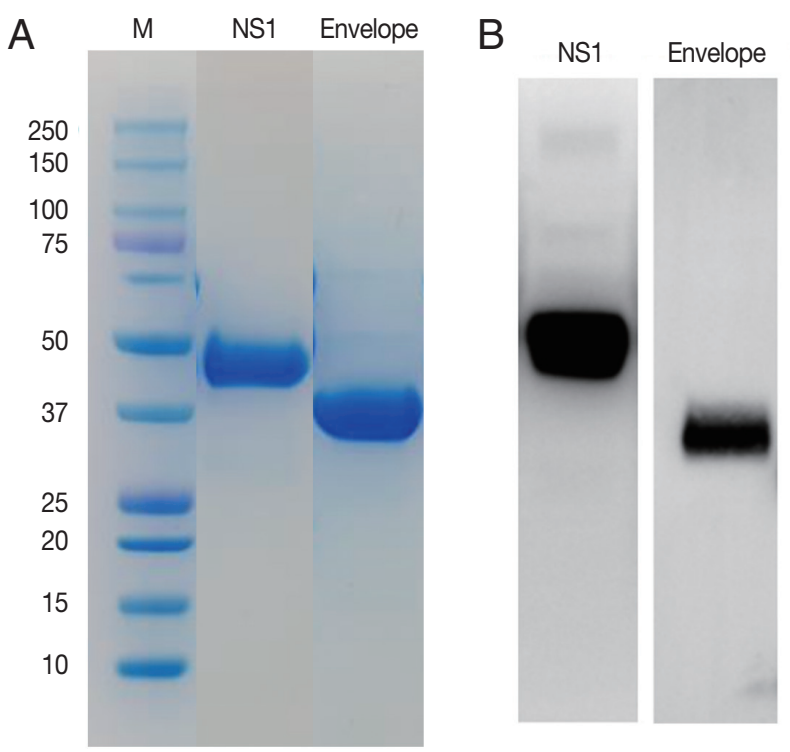

Fig. 3. Purification of the NS1 and envelope proteins of ZIKV proteins and confirmation of the antigenicity. Expressed proteins in Sf9 cells were purified in $\mathrm{Ni}^{2+}$-NTA resin (A) and tested for the antigenicity with a ZIKV infected serum in western blot (B).
These 2 sequences are located adjacent to each other in the genome. Using these sequences, the ZIKV proteins were successfully expressed in Sf9 cells and purified as 37 and $45 \mathrm{kDa}$ of molecular weight (Fig. 3).

Monoclonal antibodies showing high affinity constant to recombinant proteins were selected among the various hybridoma types. $\mathrm{IgG}_{1}$ from hybridoma J5E1 showed a 1.5 to 10 fold strong affinity $\left(5.55 \times 10^{9}\right)$ to recombinant $\mathrm{E}$ antigen compared to isotypes from other hybridomas $\left(3.12 \times 10^{8}-4.02 \times 10^{9}\right)$. On the other hand, $\operatorname{IgG}_{1}$ from hybridoma I2G7 showed an even stronger response to recombinant NS1 antigen, with a 5 to 100 fold strong affinity $\left(3.32 \times 10^{9}\right)$ to NS1 protein compared to isotypes from other hybridomas $\left(0.25 \times 10^{8}-6.22 \times 10^{8}\right)$ (Fig. 4; Table 1).

\section{Zika lgG/lgM RDT kit as a reliable diagnostic tool}

To evaluate the usage of Zika IgG/IgM RDT kit as a reliable

Table 1. Characteristics of monoclonal antibodies against ZIKV E and NS1 proteins

\begin{tabular}{|c|c|c|c|c|}
\hline Immunogen ${ }^{a}$ & Hybridoma & Isotype & $\begin{array}{l}\text { Affinity constant } \\
\text { to recombinant } \\
\text { proteins }(1 / \mathrm{Kd})\end{array}$ & $\begin{array}{c}\text { Reactivity in } \\
\text { rapid } \\
\text { diagnostic kitb }\end{array}$ \\
\hline \multirow[t]{4}{*}{ ZIKVE } & J5E1 & $\lg G_{1}$ & $5.55 \times 10^{9}$ & $\begin{array}{l}\text { Yes, for gold } \\
\text { conjugate }\end{array}$ \\
\hline & J1A7 & $\lg G_{2 a}$ & $3.12 \times 10^{8}$ & Yes \\
\hline & J5E4 & $\operatorname{lgG}_{1}$ & $6.13 \times 10^{8}$ & Yes \\
\hline & A136 & $\lg _{1}$ & $4.02 \times 10^{9}$ & Yes \\
\hline \multirow[t]{5}{*}{ ZIKV NS1 } & J2G7 & $\lg G_{1}$ & $3.32 \times 10^{9}$ & $\begin{array}{c}\text { Yes, for gold } \\
\text { conjugate }\end{array}$ \\
\hline & J3B1 & $\lg _{1}$ & $1.12 \times 10^{8}$ & Yes \\
\hline & J10A5 & $\lg _{1}$ & $6.22 \times 10^{8}$ & Yes \\
\hline & J16C9 & $\operatorname{lgG}_{1}$ & $2.12 \times 10^{8}$ & No \\
\hline & J10C6 & $\lg M$ & $0.25 \times 10^{8}$ & Yes \\
\hline
\end{tabular}

almmunogen: recombinant ZIKV envelope (E) and nonstructural 1 (NS1) proteins.

bScreening: ZIKV purified by ultracentrifugation.

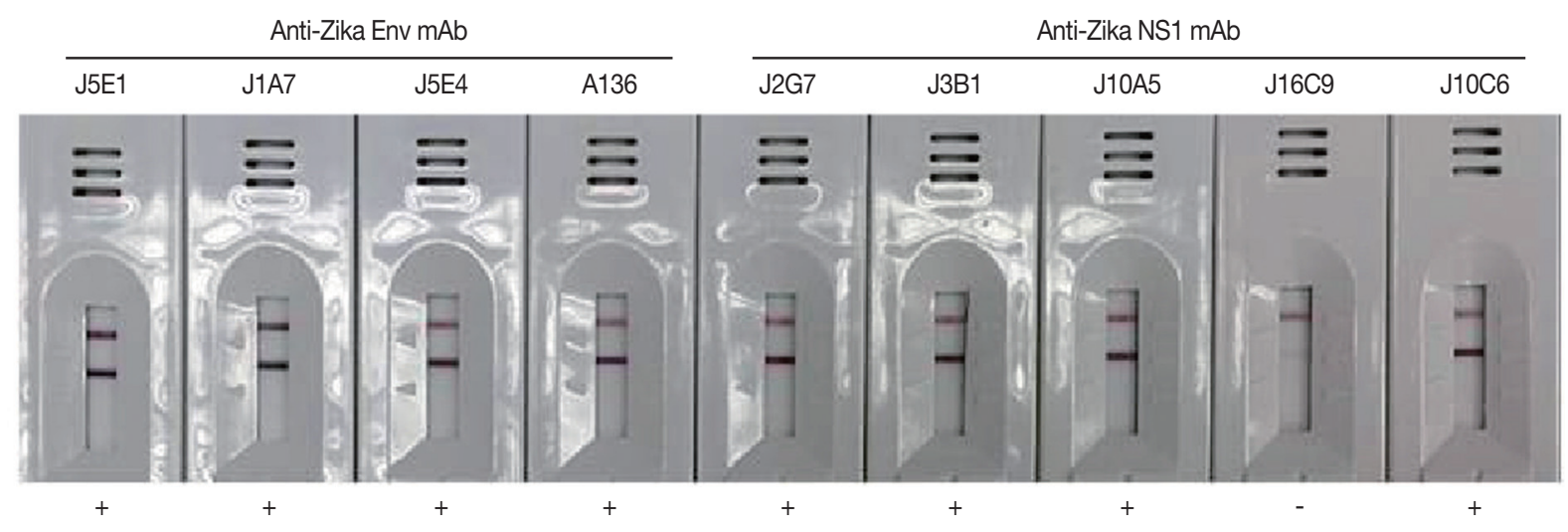

Fig. 4. Efficacy of the cloned monoclonal antibodies against E and NS1 proteins of ZIKV in RDT kits. Each mAb was conjugated with gold particles and reacted in the test line of the purified ZIKV for selection of useful specific mAb clones. 


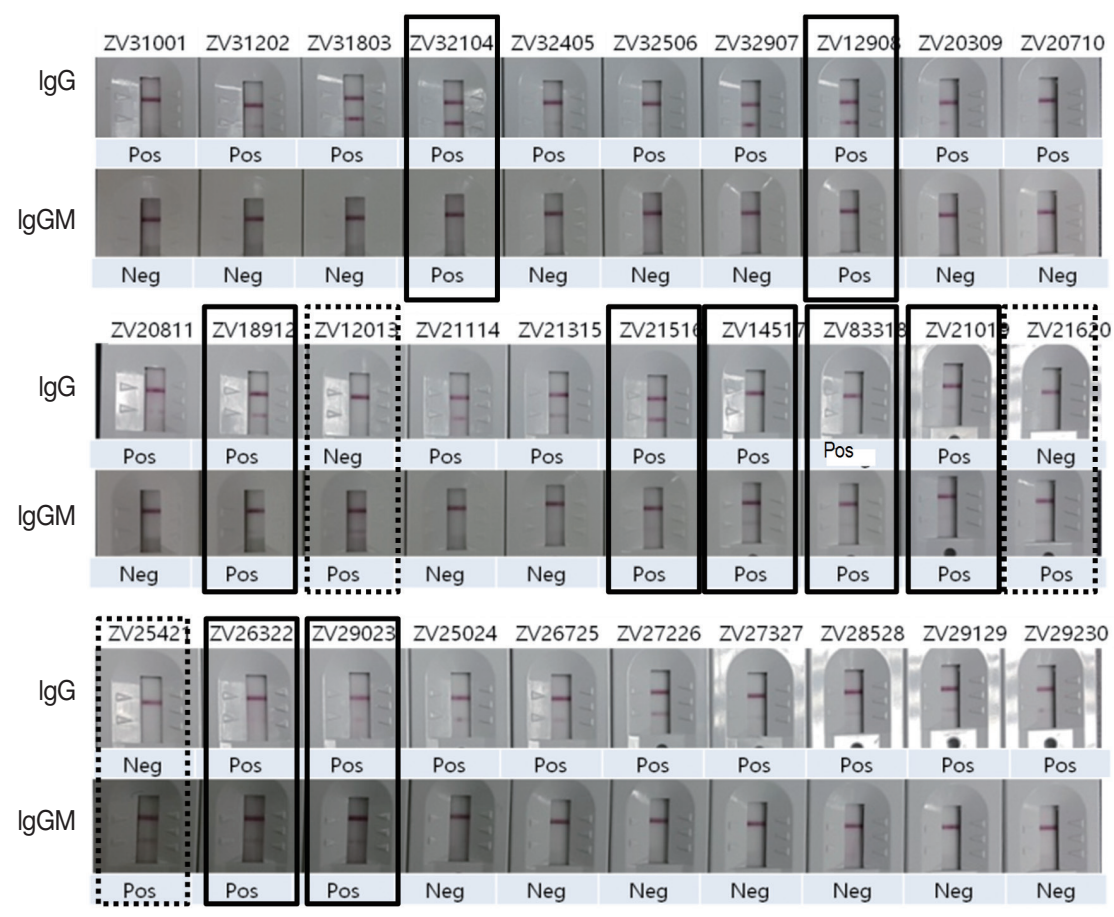

Fig. 5. Comparison of ZIKV lgG/lgM RDT results with 30 Zika positive sera of confirmed ELISA, PRNT, and PCR results. Real lines showed positive in both lgG and lgM, dotted lines positive only in $\operatorname{lgM}$, and the remainders positive only in lgG.

Table 2. Comparison test of Zika lgG/lgM RDT kit using 30 Zika positive sera

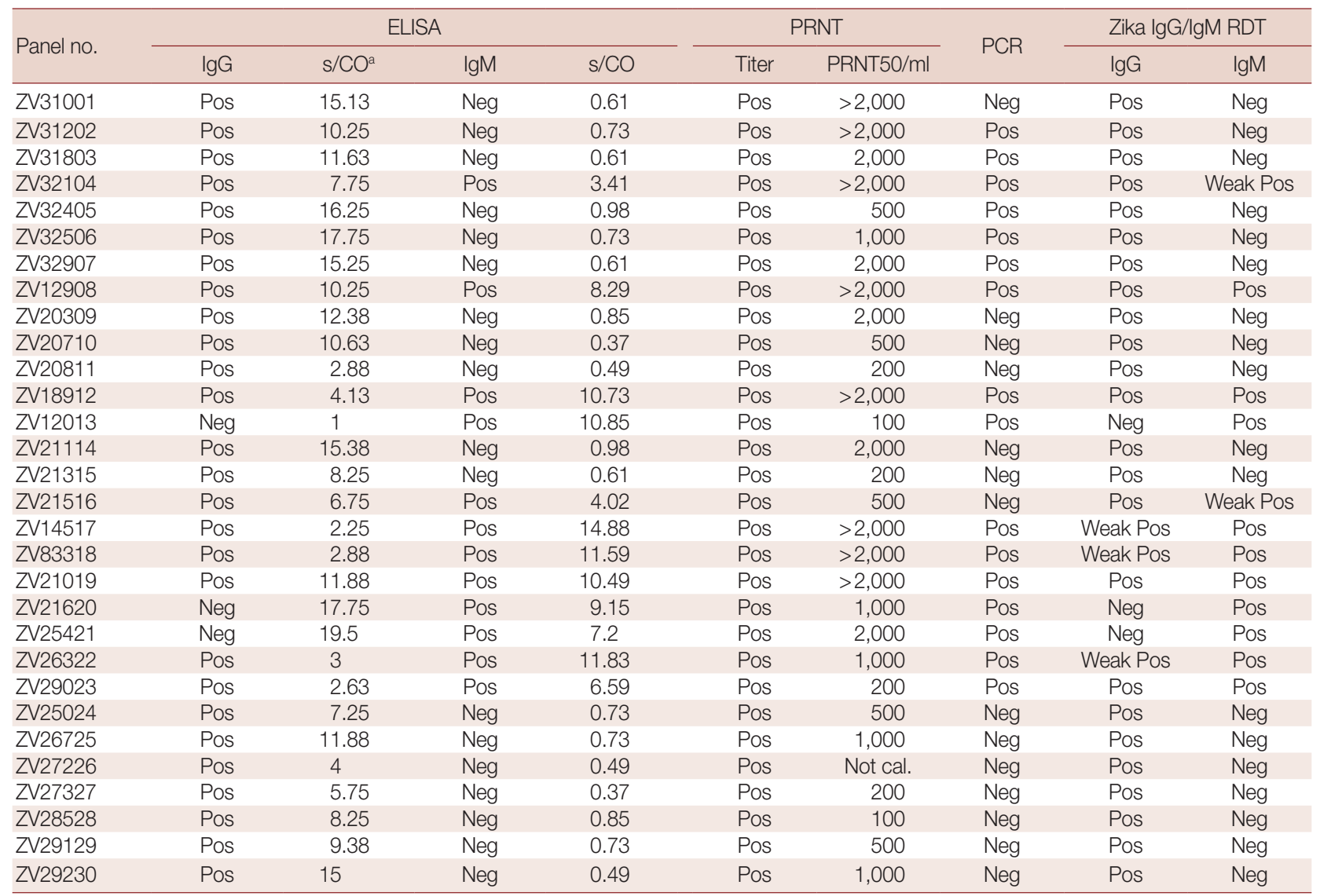

${ }^{a} \mathrm{~S} / \mathrm{CO}$ : signal per cut-off value. 
Table 3. Sensitivity and specificity of Zika RDT in field test

\begin{tabular}{|c|c|c|c|c|}
\hline \multirow{2}{*}{\multicolumn{2}{|c|}{$N=600$ (ZIKV lgG test) }} & \multicolumn{2}{|c|}{ ELISA } & \multirow{2}{*}{ Total } \\
\hline & & Positive & Negative & \\
\hline This kit & $\begin{array}{l}\text { Positive } \\
\text { Negative }\end{array}$ & $\begin{array}{r}297 \\
3\end{array}$ & $\begin{array}{r}2 \\
298\end{array}$ & $\begin{array}{l}299 \\
301\end{array}$ \\
\hline \multicolumn{2}{|l|}{ Total } & 300 & 300 & 600 \\
\hline \multirow{2}{*}{\multicolumn{2}{|c|}{$\mathrm{N}=450$ (ZIKV lgM test) }} & \multicolumn{2}{|c|}{ ELISA } & \multirow{2}{*}{ Total } \\
\hline & & Positive & Negative & \\
\hline This kit & $\begin{array}{l}\text { Positive } \\
\text { Negative }\end{array}$ & $\begin{array}{r}145 \\
5\end{array}$ & $\begin{array}{r}4 \\
296\end{array}$ & $\begin{array}{l}149 \\
301\end{array}$ \\
\hline Total & & 150 & 300 & 450 \\
\hline
\end{tabular}

Positive samples were provided from the Hospital Gaffree e Guinle (Rio de Janeiro, Brazil) and Ministry of Bahia (Brazil) in 2016. Negative samples were provided from the Dankook University Hospital (Cheonan, Korea) in 2016.

Table 4. Cross-reaction with DENV positive and negative sera of PVD201

\begin{tabular}{|c|c|c|c|c|c|}
\hline \multirow{2}{*}{ Panel name } & & \multicolumn{2}{|c|}{ Titer (by SD DENV IgG/IgM Capture ELISA) } & \multicolumn{2}{|c|}{ Zika RDT } \\
\hline & & $\operatorname{lgG}, \mathrm{s} / \mathrm{CO}^{\mathrm{b}}$ & $\operatorname{lgM}, \mathrm{s} / \mathrm{CO}$ & ZIKV IgG & ZIKV IgM \\
\hline \multirow[t]{18}{*}{ PVD201 ${ }^{a}$} & PVD201-01 & $>8.9$ & 6 & Positive & Negative \\
\hline & PVD201-02 & 1.6 & 0.4 , Negative & Negative & Negative \\
\hline & PVD201-03 & 1.1 & 0.3 , Negative & Negative & Negative \\
\hline & PVD201-05 & 1.9 & 0.5 , Negative & Negative & Negative \\
\hline & PVD201-06 & 3.4 & 2.6 & Negative & Negative \\
\hline & PVD201-07 & 8.8 & $>7.7$ & Negative & Negative \\
\hline & PVD201-08 & 1.2 & 1 & Negative & Negative \\
\hline & PVD201-09 & 2.1 & 1.2 & Negative & Negative \\
\hline & PVD201-10 & 2.5 & $>7.7$ & Negative & Positive \\
\hline & PVD201-11 & 1 & 0.4, Negative & Negative & Negative \\
\hline & PVD201-12 & 0.7, Negative & 0.4 , Negative & Negative & Negative \\
\hline & PVD201-14 & 2.1 & 0.6, Negative & Negative & Negative \\
\hline & PVD201-16 & 2.4 & 6.8 & Negative & Negative \\
\hline & PVD201-17 & $>8.9$ & 5.5 & Positive & Negative \\
\hline & PVD201-18 & 0.7, Negative & 0.8 , Negative & Negative & Negative \\
\hline & PVD201-19 & 0.5 , Negative & 0.4, Negative & Negative & Negative \\
\hline & PVD201-20 & 3 & $>7.7$ & Negative & Negative \\
\hline & PVD201-21 & $>8.9$ & 3.9 & Positive & Negative \\
\hline
\end{tabular}

aanti-Dengue Mixed Titer Perform Panel.

${ }^{b_{S}} / C O$, signal per cut-off ratio measured by ELISA. All 4 serotypes of DENV are contained in the panels.

diagnostic tool, a comparison test using 30 Zika Mixed Titer Standards showed $100 \%$ identical results with the RDT kit against ELISA, PRNT and PCR (Fig. 5; Table 2). The diagnostic accuracy of Zika RDT as determined by sensitivity and specificity in a field test was fairly high; with sensitivity and specificity for $\operatorname{IgG}$ at 99.0 and $99.3 \%$, respectively, while for IgM it was 96.7 and $98.7 \%$, respectively (Table 3).

Cross reactions with DENV were also determined, in which Zika RDT showed cross-reaction with PVD201 in 16.7\% and $5.6 \%$ in IgG and IgM, respectively from a total of 18 panels (Table 4). The results showed that all the cross reactions were identified at high titer (>8.9 s/CO) of DENV antibody posi- tives. Fortunately, no cross-reaction with anti-West Nile virus, anti-yellow fever virus, anti-HCV were observed.

\section{DISCUSSION}

To detect ZIKV RNA early in the course of illness, real-time RT-PCR (rRT-PCR) on serum and urine has been commonly used during the first 2 weeks after onset of the illness [34]. Although a number of real-time ZIKV RT-PCR assays have been described, a recent evaluation showed that some had low sensitivity and incompatibility with currently circulating epidemic ZIKV strains belonging to the Asian/American lineage [25]. 
Additionally, an estimated $20-80 \%$ of ZIKV-infected patients may be undiagnosed because of the low viral loads in these patient's clinical specimens [25]. Thus, serologic test for ZIKV to detect ZIKV-specific IgM and neutralizing antibodies have been developed. Since IgM and neutralizing antibodies against ZIKV are detectable up to 12 weeks after onset of illness, serology tests should be followed when ZIKV RNA is negative on serum and urine from suspicious ZIKV infected patients.

In the present study, we successfully applied gold conjugate for the development of a rapid diagnostic testing (RDT) system with the monoclonal antibodies J5E1 and J2G7 that correspond to the envelope (E) and non-structural 1 (NS1) proteins of ZIKV, respectively. Serological diagnosis of ZIKV is far from easy because of extensive cross-reactivity between antibodies against other flaviviruses [35]. With the baculovirus expression system, we can obtain soluble expressed and highly purified recombinant $\mathrm{E} \& \mathrm{NS} 1$ proteins of ZIKV, and the resultant sensitivity and specificity of Zika RDT were excellent. Zika RDT showed 100\% identical results with the standard panel using ELISA and PRNT. Zika RDT requires neither electricity nor any specific laboratory equipment. It is stable at $4-30^{\circ} \mathrm{C}$ and has a long shelf life. It is simple to use so the assay is fast, and avoids blood being drawn from suspicious patients. These characteristics make it useful in a field setting.

However, some cross-reaction with the DENV (16.7\% and $5.6 \%$ for IgG and IgM, respectively) was observed. Fortunately, there was no cross-reaction with anti-West Nile virus, anti-yellow fever virus, anti-HCV serums. While the flavivirus NS1) is secreted by infected cells and is involved in immune evasion and pathogenesis [36]. Distinct features that may be related to the ZIKV neurotropism of the E protein $[37,38]$ and different electrostatic characteristics of the NS1 protein [39] would result in the high efficacy of our RDT and its differentiating of other flavivirus infections.

The cross-reaction with DENV represents 1 major disadvantage of the test. Presumed causes of cross-reaction of Zika RDT to DENV may be caused by mixed infection of ZIKV and DENV both in vectors and in human, and overlapping clinical symptoms make differential diagnosis a problem. ZIKV and DENV show a higher than $50 \%$ homology in E and NS1 proteins [38], and these common antigenic determinants may confuse the issue. Pre-existing immunity to prior DENV infection might also increase ZIKV replication through antibodydependent enhancement (ADE) of ZIKV infection [40] causing variable results. In this context, cross-reactivity between
DENV and ZIKV seems inevitable. Indeed, it has been suggested that ZIKV must be considered another member of the DENV serocomplex [40].

Zika RDT was the first to be developed, and the first to receive Brazilian Health Regulatory Agency (ANVISA) approval of ZIKV rapid test from the Brazilian government by the cooperation of BahiaFarma (Bahia, Brazil) and GenBody Inc. (Cheonan, Korea). As it has been proved to be effective in the field, promotion of ZIKV test for public healthcare awareness has been facilitated. The Zika RDT kit is very simple to use, rapid to assay, and very sensitive and highly specific. Therefore, it would serve as a choice of method for point-of-care diagnosis and large scale surveys of ZIKV infection among people under clinical or field conditions worldwide in endemic areas.

Though the test has been proved effective, further studies are needed to address other significant problems. Co-infection of DENV, ZIKV, chikungunya virus, and other yet unknown viral diseases need to be evaluated, and their co-infection rates determined. The need to differentiate these infections in a single sample for both clinical and epidemiologic purposes is of immediate importance and is likely to remain relevant in the future. Additionally, the relationship between ZIKV variants and severe complications such as microcephaly and Guillain-Barre syndrome also need to be addressed, and our test seems flexible enough to detect these variants.

\section{ACKNOWLEDGMENT}

This research was supported by the Bio \& Medical Technology Development Program of the National Research Foundation (NRF) funded by the Korean Government (MSIP) (no. 2016M3A9B6919217).

\section{CONFLICT OF INTEREST}

The authors declare that there is no conflict of interest.

\section{REFERENCES}

1. Dick GW. Zika virus. II. Pathogenicity and physical properties. Trans R Soc Trop Med Hyg 1952; 46: 521-534.

2. Macnamara FN. Zika virus: a report on three cases of human infection during an epidemic of jaundice in Nigeria. Trans R Soc Trop Med Hyg 1954; 48: 139-145.

3. Marchette NJ, Garcia R, Rudnick A. Isolation of Zika virus from Aedes aegypti mosquitoes in Malaysia. Am J Trop Med Hyg 1969; 
18: 411-415.

4. Duffy MR, Chen TH, Hancock WT, Powers AM, Kool JL, Lanciotti RS, Pretrick M, Marfel M, Holzbauer S, Dubray C, Guillaumot L, Griggs A, Bel M, Lambert AJ, Laven J, Kosoy O, Panella A, Biggerstaff BJ, Fischer M, Hayes EB. Zika virus outbreak on Yap Island, Federated States of Micronesia. N Engl J Med 2009; 360: 2536-2543.

5. Campos GS, Bandeira AC, Sardi SI. Zika virus outbreak, Bahia, Brazil. Emerg Infect Dis 2015; 21: 1885-1886.

6. Oehler E, Watrin L, Larre P, Leparc-Goffart I, Lastere S, Valour F, Baudouin L, Mallet H, Musso D, Ghawche F. Zika virus infection complicated by Guillain-Barré syndrome--case report, French Polynesia, December 2013. Euro Surveill 2014; 19.

7. Triunfol M. A new mosquito-borne threat to pregnant women in Brazil. Lancet Infect Dis 2016; 16: 156-157.

8. Chan JF, Choi GK, Yip CC, Cheng VC, Yuen KY. Zika fever and congenital Zika syndrome: an unexpected emerging arboviral disease. J Infect 2016; 72: 507-524.

9. Pessôa R, Patriota JV, Lourdes de Souza Md, Felix AC, Mamede N, Sanabani SS. Investigation into an outbreak of dengue-like illness in Pernambuco, Brazil, revealed a cocirculation of Zika, chikungunya, and Dengue virus type 1. Medicine (Baltimore) 2016; 95: e3201.

10. Sardi SI, Somasekar S, Naccache SN, Bandeira AC, Tauro LB, Campos GS, Chiu CY. Coinfections of Zika and chikungunya viruses in Bahia, Brazil, identified by metagenomic next-generation sequencing. J Clin Microbiol 2016; 54: 2348-2353.

11. Musso D, Gubler DJ. Zika virus. Clin Microbiol Rev 2016; 29 : 487-524.

12. Musso D, Roche C, Robin E, Nhan T, Teissier A, Cao-Lormeau VM. Potential sexual transmission of Zika virus. Emerg Infect Dis 2015; 21: 359-361.

13. Foy BD, Kobylinski KC, Chilson Foy JL, Blitvich BJ, Travassos da Rosa A, Haddow AD, Lanciotti RS, Tesh RB. Probable non-vector-borne transmission of Zika virus, Colorado, USA. Emerg Infect Dis 2011; 17: 880-882.

14. Calvet G, Aguiar RS, Melo ASO, Sampaio SA, de Filippis I, Fabri A, Araujo ESM, de Sequeira PC, de Mendonça MCL, de Oliveira L, Tschoeke DA, Schrago CG, Thompson FL, Brasil P, Dos Santos FB, Nogueira RMR, Tanuri A, de Filippis AMB. Detection and sequencing of Zika virus from amniotic fluid of fetuses with microcephaly in Brazil: a case study. Lancet Infect Dis 2016; 16: 653-660.

15. To KK, Chan JF, Chen H, Li L, Yuen KY. The emergence of influenza A H7N9 in human beings 16 years after influenza A H5N1: a tale of two cities. Lancet Infect Dis 2013; 13: 809-821.

16. Chan JF, Lau SK, To KK, Cheng VC, Woo PC, Yuen KY. Middle East respiratory syndrome coronavirus: another zoonotic betacoronavirus causing SARS-like disease. Clin Microbiol Rev 2015; 28: 465-522.

17. To KK, Chan JF, Tsang AK, Cheng VC, Yuen KY. Ebola virus disease: a highly fatal infectious disease reemerging in West Africa. Microbes Infect 2015; 17: 84-97.
18. Waggoner JJ, Pinsky BA. Zika virus: diagnostics for an emerging pandemic threat. J Clin Microbiol 2016; 54: 860-867.

19. Lanciotti RS, Kosoy OL, Laven JJ, Velez JO, Lambert AJ, Johnson AJ, Stanfield SM, Duffy MR. Genetic and serologic properties of Zika virus associated with an epidemic, Yap State, Micronesia, 2007. Emerg Infect Dis 2008; 14: 1232-1239.

20. Faye O, Faye O, Dupressoir A, Weidmann M, Ndiaye M, Alpha Sall A. One-step RT-PCR for detection of Zika virus. J Clin Virol 2008; 43: 96-101.

21. Balm MN, Lee CK, Lee HK, Chiu L, Koay ES, Tang JW. A diagnostic polymerase chain reaction assay for Zika virus. J Med Virol 2012; 84: 1501-1505.

22. Faye O, Faye O, Diallo D, Diallo M, Weidmann M, Sall AA. Quantitative real-time PCR detection of Zika virus and evaluation with field-caught mosquitoes. Virol J 2013; 10: 311.

23. Pyke AT, Daly MT, Cameron JN, Moore PR, Taylor CT, Hewitson GR, Humphreys JL, Gair R. Imported Zika virus infection from the Cook islands into Australia, 2014. PLoS Curr 2014; 6 .

24. Goebel S, Snyder B, Sellati T, Saeed M, Ptak R, Murray M, Bostwick R, Rayner J, Koide F, Kalkeri R. A sensitive virus yield assay for evaluation of antivirals against Zika virus. J Virol Methods 2016; 238: 13-20.

25. Corman VM, Rasche A, Baronti C, Aldabbagh S, Cadar D, Reusken CB, Pas SD, Goorhuis A, Schinkel J, Molenkamp R, Kümmerer BM, Bleicker T, Brünink S, Eschbach-Bludau M, EisHübinger AM, Koopmans MP, Schmidt-Chanasit J, Grobusch MP, de Lamballerie X, Drosten C, Drexler JF. Assay optimization for molecular detection of Zika virus. Bull World Health Organ 2016; 94: 880-892.

26. Gourinat AC, O'Connor O, Calvez E, Goarant C, DupontRouzeyrol M. Detection of Zika virus in urine. Emerg Infect Dis 2015; 21: 84-86.

27. Musso D, Roche C, Nhan TX, Robin E, Teissier A, Cao-Lormeau VM. Detection of Zika virus in saliva. J Clin Virol 2015; 68: 5355.

28. Bingham AM, Cone M, Mock V, Heberlein-Larson L, Stanek D, Blackmore C, Likos A. Comparison of test results for Zika virus RNA in urine, serum, and saliva specimens from persons with travel-associated Zika virus disease - Florida, 2016. MMWR Morb Mortal Wkly Rep 2016; 65: 475-478.

29. Lustig Y, Mendelson E, Paran N, Melamed S, Schwartz E. Detection of Zika virus RNA in whole blood of imported Zika virus disease cases up to 2 months after symptom onset, Israel, December 2015 to April 2016. Euro Surveill 2016; 21.

30. Köhler G, Milstein C. Continuous cultures of fused cells secreting antibody of predefined specificity. Nature 1975; 256: 495497.

31. Galfrè G, Milstein C. Preparation of monoclonal antibodies: strategies and procedures. Methods Enzymol 1981; 73: 3-46.

32. Friguet B, Chaffotte AF, Djavadi-Ohaniance L, Goldberg ME. Measurements of the true affinity constant in solution of antigen-antibody complexes by enzyme-linked immunosorbent assay. J Immunol Methods 1985; 77: 305-319. 
33. Chong CK, Jeong W, Kim HY, An DJ, Jeoung HY, Ryu JE, Ko AR, Kim YJ, Hong SJ, Yang Z, Nam HW. Development and clinical evaluation of a rapid serodiagnostic test for toxoplasmosis of cats using recombinant SAG1 antigen. Korean J Parasitol 2011; 49: 207-212.

34. Paz-Bailey G, Rosenberg ES, Doyle K, Munoz-Jordan J, Santiago GA, Klein L, Perez-Padilla J, Medina FA, Waterman SH, Gubern CG, Alvarado LI, Sharp TM. Persistence of Zika virus in dody fluids - preliminary report. N Engl J Med 2017.

35. Vorou R. Letter to the editor: diagnostic challenges to be considered regarding Zika virus in the context of the presence of the vector Aedes albopictus in Europe. Euro Surveill 2016; 21: 30161.

36. Muller DA, Young PR. The flavivirus NS1 protein: molecular and structural biology, immunology, role in pathogenesis and application as a diagnostic biomarker. Antiviral Res 2013; 98: 192208.
37. Dai L, Song J, Lu X, Deng YQ, Musyoki AM, Cheng H, Zhang Y, Yuan Y, Song H, Haywood J, Xiao H, Yan J, Shi Y, Qin CF, Qi J, Gao GF. Structures of the Zika virus envelope protein and its complex with a flavivirus broadly protective antibody. Cell Host Microbe 2016; 19: 696-704.

38. Sirohi D, Chen Z, Sun L, Klose T, Pierson TC, Rossmann MG, Kuhn RJ. The 3.8 The 3.8 A resolution cryo-EM structure of Zika virus. Science 2016; 352: 467-470.

39. Song H, Qi J, Haywood J, Shi Y, Gao GF. Zika virus NS1 structure reveals diversity of electrostatic surfaces among flaviviruses. Nat Struct Mol Biol 2016; 23: 456-458.

40. Dejnirattisai W, Supasa P, Wongwiwat W, Rouvinski A, BarbaSpaeth G, Duangchinda T, Sakuntabhai A, Cao-Lormeau VM, Malasit P, Rey FA, Mongkolsapaya J, Screaton GR. Dengue virus sero-cross-reactivity drives antibody-dependent enhancement of infection with Zika virus. Nat Immunol 2016; 17: 1102-1108. 